Archaeological Journal

\title{
Notes on a Door Lock
}

\section{R. S. Ferguson F.S.A.}

To cite this article: R. S. Ferguson F.S.A. (1899) Notes on a Door Lock, Archaeological Journal, 56:1, 180-183, DOI: $10.1080 / 00665983.1899 .10852818$

To link to this article: http://dx.doi.org/10.1080/00665983.1899.10852818

$$
\text { 曲 Published online: } 16 \text { Jul } 2014 .
$$

Submit your article to this journal $\widetilde{ }$

Џ Article views: 2

Q View related articles $\asymp$ 


\section{NOTES ON A DOOR LOCK.}

By R. S. FERGUSON, F.S.A., Chancellor of the Diocese of Carlisle.

I have the honour to exhibit two photographs (No. 1 front and No. 2 back) of a large door lock, which was presented to the Museum in Tullie House, Carlisle, by our late member, Mr. Robert Ferguson, F.S.A. No history is known of this lock. Mr. Ferguson purchased it from a dealer for the purpose of adding it to the curious collection of locks and keys in the Museum-a collection in which he took much interest.

The lock is about 2 feet 1 inch in length, and in breadth is 7 inches at the fore end, or end nearest the door post on which it falls to. The rim or flange of the lock is provided with fifteen bolt-holes for the purpose of fastening it to a door. ${ }^{1}$

Classified according to its construction, this is a warded lock ; classified according to the purpose to which it is to be applied it is a spring draw-back lock-that is, a lock whose bolts, when the door is closed, to which the lock is fixed, automatically spring to and fasten the door, requiring to be drawn back by a handle or key before the door can be opened. The lock under consideration has three bolts, and the box or case of the lock is prolonged so as completely to cover the ends of the bolts, which shoot into a staple on the door-post on which the door falls to; thus, when the door is closed, the box of the lock covers the works, the bolts, and the staple, so that pressure cannot be brought to bear on the ends of the bolts in order to force the lock open, which otherwise would be quite possible; in fact, now that the springs are rather weak from age, I can force the bolts back with my thumb. I have said that this lock is,

1 In the photograph of the front of the lock, two or three of these holes are occupied by modern screw-heads, which were used to hold the lock in position before the camera. A string does that work in the photograph of the back. 
To face page 179 .

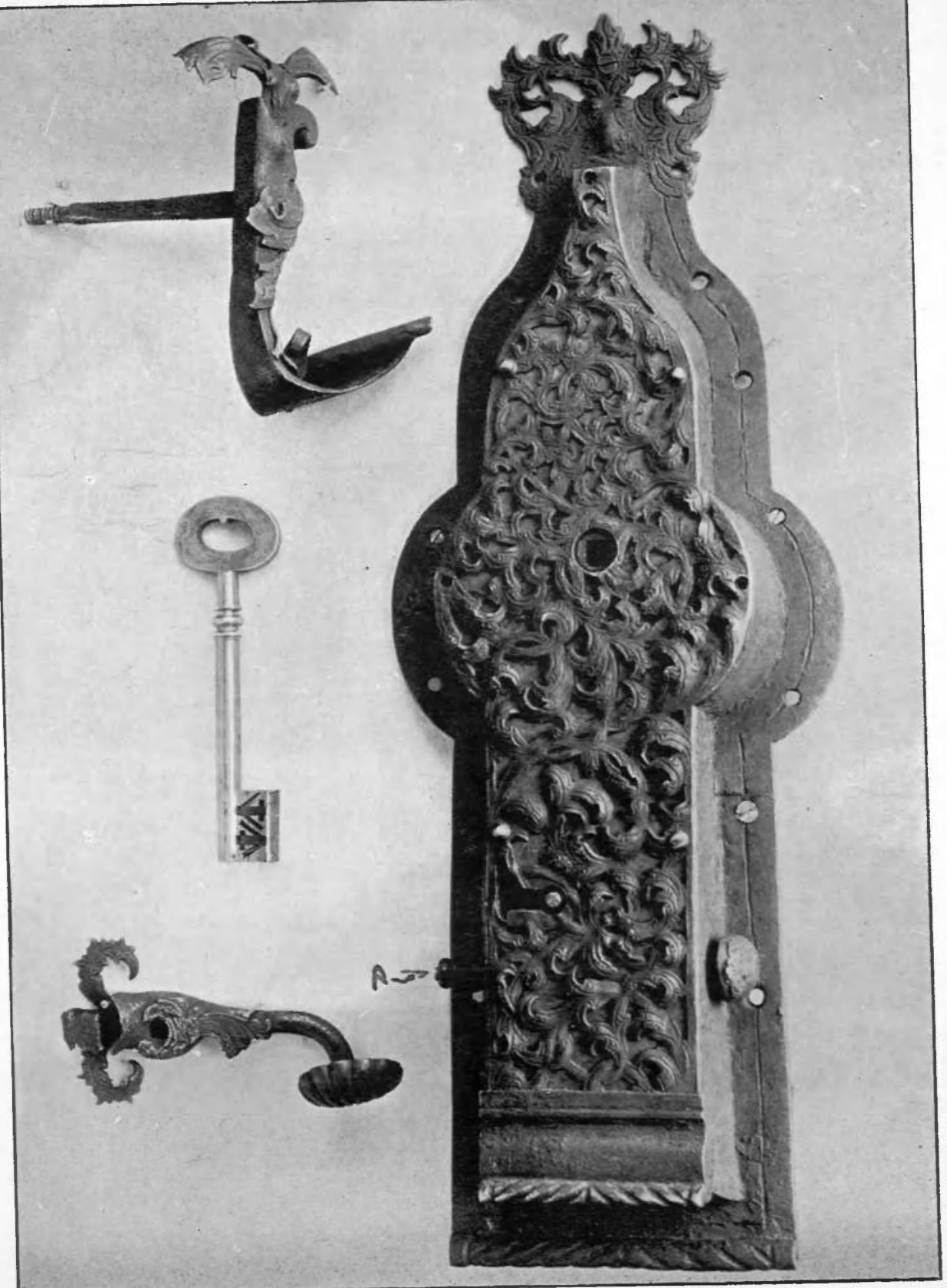

 


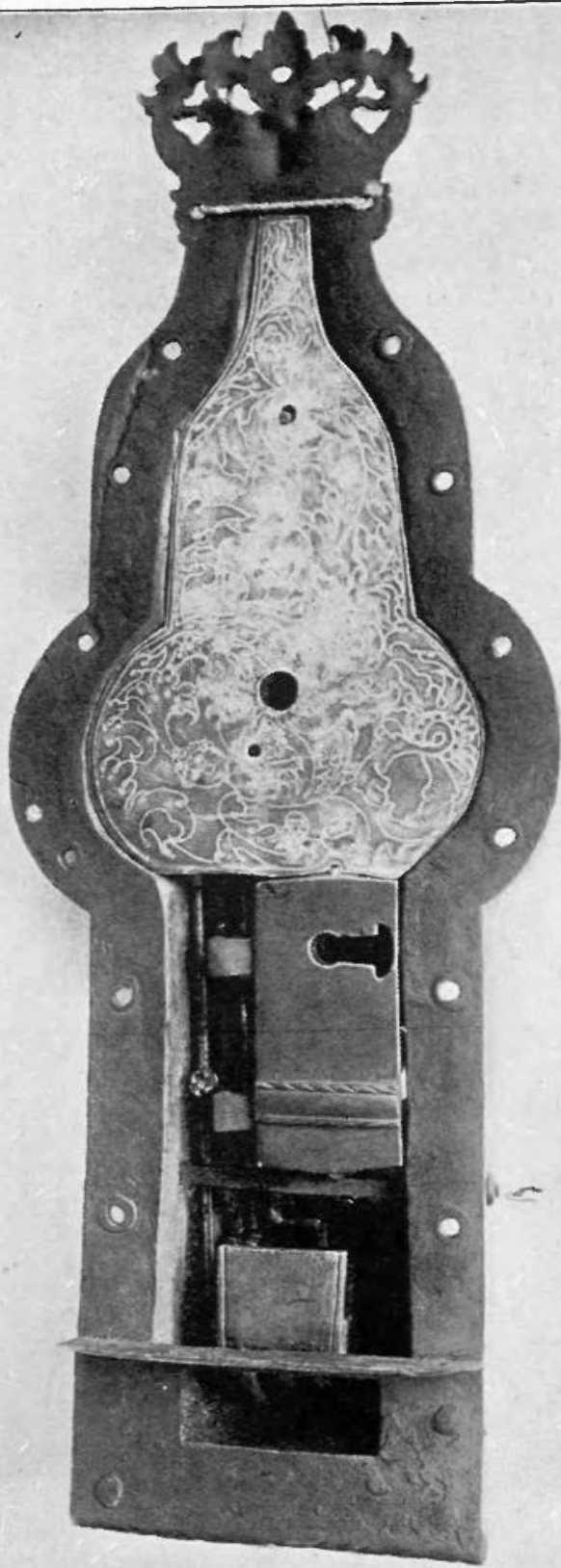

울 
as regards its construction, a warded lock. A warded lock is one in which there are wards, certain contrivances or bariers for preventing the passage of the key, unless its web or bitt has clefts cut in it to fit the wards. The wards of a lock, and consequently the clefts of the bitt of its key, are frequently very complicated. The wards, or wheels, in this lock are fairly so, as you may see from the photograph of the key (Photograph No. 1). ${ }^{1}$ As is generally the case, the clefts in the lower half of the bitt of this key are exactly the same as those in the upper half, only reversed, that is, the other way up. Such keys generally have solid stems, and can open a lock from either side, the upper half of the bitt being employed to open the lock from the one side, and the lower half from the other side. A key with a pipe or barrel, fitting on a pin or pipe-shaft, can only open a lock on one side. To that rule this key is an exception: it has a pipe or barrel, fitting on a pin, and yet can open this lock from either side. On looking at the pliotographs of the locks, a keyhole is seen on both the front and the back of the lock. But these key-holes are not opposite to one another--they do not run through the lock; there is no key-hole that the curious can clap ear or eye against. The fact is that this lock contains duplicate sets of works or wards, one set in advance of the other about 2 inches. The set nearest to the fore-end of the lock has a key-hole to the front of the lock; the set nearest to the butt has a keyhole to the back of the lock. ${ }^{2}$ There is a handle on each side of the lock, and a catch or pin with a large head drops vertically through the box of the lock, between the front key-hole and the fore end of the lock. This catch under certain circumstances drops and fastens back the top and bottom bolts of the three. When not so engaged its head stands up nearly a quarter of an inch above the upper side

1 'This key, as is apparent at a glance, is not coeral with the lock; as a matter of fact, it was made a few weeks ago, since the lock came into the possession of the Museum. But it is an honest key, accurately fitting and traversing the wards of the lock, and not erading them, as a master key, or a picklock does. It cost $16 s$, and is a clerer piece of smith's mork.
? The key-hole to the front has a pin to receire the pipe of the key; the one to the back has not. I see no reason $f \propto r$ the difference. In neither key-hole can the k+s be turned rousd the whole circle-it can only be turned a little past the half-circle, and must be turned backwards before it can be withdrawn. 
of the box of the lock. ${ }^{1}$ All the three bolts are then free to act, and if the door be shut to, they shoot under the staple on the door-post placed for their reception, and the door is then locked and cannot be opened without the key.

To open the door from the outside, two operations are necessary: firstly, to insert the key and turn it as far as it will go-it draws back the top and bottom bolts-the catch then drops automatically, and these two bolts are fastened back; secondly, to draw back the middle bolt by aid of the handle outside of the door; the door can then be pulled open. If the catch be not raised, the lock becomes a simple one-bolt draw-back lock, opened from either side by depressing a handle, without using the key at all. The worn condition of the end of the middle bolt compared with the ends of the other two shows that the lock was generally used in this way, and for this purpose it has a handle on each side.

To open the door from the inside requires only one operation, viz., to insert the key, and turn it as far as it will go-it draws all three of the bolts-the catch or pin fall drops and fastens back the top and bottom bolts, and the door can be pushed open. The lock has also become a simple one-bolt draw-back lock as before. It should be noticed that the catch or pin is an excellent tell-tale as to whether the door is locked or not: when the head of the catch sits down on the side of the box of the lock, the door can be opened by either of the handles; when the head is a little way above the side, the door is locked and the key is required.

The front of the box of the lock is covered by wrought iron scroll work representing conventional foliage; it is backed by a thin sheet of yellow metal, which shows through the interstices of the scroll work. The back of the box is partially covered by a thin sheet of white metal. This has lightly engraved upon it the figure of a coarse-featured woman amid scrolls of foliage. One wonders why ornament is wasted here, where it must be concealed when the lock is fastened to a door.

1 Its head and tail are seen in this position in the photograph of the front of the lock, No.1. The photograph of the back, No. 2, shows part of the works of the lock including this bolt. 
This lock is remarkable as an example of the blacksmith's art, but not of the locksmith's craft. Admirable as it may be as a specimen of iron work, it is contemptible as a lock: it would be easy to make a skeleton key or a picklock that would evade the wards and act upon the bolts.

Various conjectures have been made about its use. A prison lock was an obvious suggestion, and the independent key-holes, one on either side, somewhat favoured the idea, for the locks of the great prisons of Paris are said to have required two men to open them, the chief turnkey on one side and the sergeant of the guard on the other, each with his key. But that idea was. knocked on the head, when it was found that one and the same key, applied to either side, would unlock the door. Nor is it likely to be the lock of a treasure chamber; the wearing away of the end of the middle bolt shows that this lock was generally used as a spring lock, opened by its handles without the intervention of a key. Even when locked it gives no great degree of security from the operations of a thief.

I am inclined to think that this lock has been used on the door of the strong room in a bank, or other office, where were kept books, papers, etc., to which several persons had to have access during office hours. For their accommodation the catch or pin would be allowed to fall and would be kept in that position during those hours, so that the door could be opened from either side by depressing the handle. When work ceased, the door would be locked by simply pushing up the catch, but it could not be opened again until the custodian of the key - probably the senior partner or the manager-had produced it. It may be asked why should the door of a strong room be made capable of unlocking from the inside. A short story will answer that question. A friend of mine, whose strong room door had a spring lock, went inside it-the key in his pocket. Some mischievous nephews slammed the door to. It took the smiths twelve hours to open that door, and an angry man came out. He banished those nephews, and left his fine estates to a distant relative in India. 